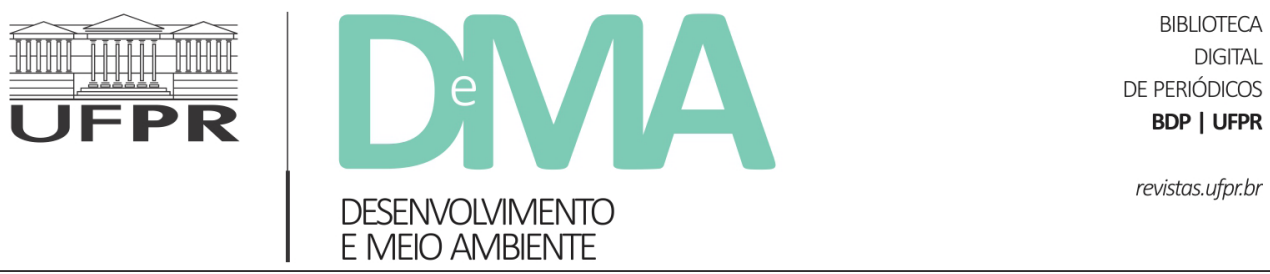

\title{
O choque do antropoceno sobre as humanidades: investigando história e ecologia a partir de Bonneuil e Moore
}

\section{Humanities under the shock of anthropocene: inquiring history and ecology from Bonneuil e Moore}

\author{
Moysés PINTO NETO ${ }^{1 *}$ \\ ${ }^{1}$ Universidade Luterana do Brasil (ULBRA), Canoas, RS, Brasil. \\ *E-mail de contato: moysespintoneto@gmail.com
}

Ensaio recebido em 23 de agosto de 2019, versão final aceita em 8 de julho de 2020, publicado em 16 de novembro de 2020 .

RESUMO: Investiga-se no trabalho o impacto do acontecimento Antropoceno sobre as Humanidades e a divisão curricular que as separa das ciências naturais. A passagem da Época geológica do Holoceno para o Antropoceno anunciada pelos cientistas da Terra faz com que o grande divisor moderno entre natureza e cultura entre em xeque. Uma vez que a própria natureza é transformada pelo impacto da tecnologia e dos sistemas sociais, a manutenção da fronteira rígida perde o sentido. Apresenta-se, heuristicamente, dois exemplos para pensar essa dupla transformação: em Bonneuil, Fressoz e Jouvancourt, é o conceito de história adotado pelos cientistas que precisa ser revisado por uma historiografia que narre as vozes vencidas na construção do Antropoceno; em Jason Moore, é o conceito de natureza que precisa ser revisado pela historiografia do capitalismo e dos sistemas-mundo. Chega-se, assim, ao conceito de geohumanidades para pensar o contexto do Antropoceno a partir do desafio de uma nova transdisciplinaridade.

Palavras-chave: antropoceno; ecologia; humanidades; história; trandisciplinaridade.

ABSTRACT: Paper examines the impact of the Anthropocene event on Humanities. The passage from the Holocene geological age to the Anthropocene brought by Earth scientists makes the great modern divide between nature and culture in check. Since nature itself is transformed by the impact of technology and social systems, the maintenance of the rigid boundary loses its meaning. Heuristically, two examples are presented to think about this double transformation: in Bonneuil, Fressoz, and Jouvancourt, it is the concept of history adopted by the scientists that need to be reviewed by historiography that listen to voices conquered in the construction of the Anthropocene; in Jason Moore, is the concept of nature that needs to be revisited by the historiography of 
capitalism and world-systems. Thus, we come to the concept of geo-humanities to think about the context of the Anthropocene.

Keywords: anthropocene; ecology; humanities; history; transdisciplinarity.

\section{Rompendo o Grande Divisor: uma investigação introdutória à temática}

A imagem das Humanidades vem sofrendo uma radical transformação nas primeiras décadas do século XXI. Por muitos focos distintos, paralelos e, por vezes, convergentes, a herança modernista que guia a separação entre ciências naturais e humanidades e seu regime atual, que divide rigidamente o mundo físico (natureza) e o mundo linguístico (cultural, social e político), sofre cada vez maiores abalos, produzindo a necessidade de significativas transformações nas articulações tradicionais curriculares ainda hoje dominadas pela divisão de trabalho moderna nas suas formas institucionais, por exemplo. E, se a imagem do abalo pode remeter, por exemplo, ao abalo sísmico, um dos eixos pelos quais se guiam esses golpes contundentes contra a "constituição moderna" é exatamente sua relação com a terra.

O conceito de Antropoceno deriva do trabalho do químico Paul Crutzen, que, analisando os efeitos da sociedade industrial sobre o ecossistema, passa a considerar que saímos da era geológica do Holoceno para habitar um mundo em que o impacto da atividade humana equivale a uma força da natureza (Crutzen, 2005). Segundo Bruno Latour (2014, p. 29-31), o $34^{\circ}$ Congresso Internacional de Geologia propunha-se a examinar a questão e oficialmente declarar - ou não - se a Terra entrou em uma nova época. Apesar disso, para frustração do nosso ansioso antropólogo da ciência, os geólogos resolveram adiar a decisão a fim de consolidar mais estudos. A temporalidade dos estudos geológicos, não por acaso, seria outra em relação às humanidades. No entanto, ainda seguindo Latour (2014), segundo a Comissão de Estratigrafia incumbida da investigação, já seria possível afirmar que o anthropos é responsável pela modificação das bacias hidrográficas, pela produção e circulação do ciclo do nitrogênio, pelo desmatamento e erosão acelerada, pelo impacto significativo no ciclo de carbono e cumplicidade da desaparição das espécies, ao ponto de ser o causador da "sexta extinção global". Os mesmos atributos que colocavam o anthropos como suposto "senhor da natureza" são os que produziram os atuais problemas ecológicos. "O mestre como escravo" ou "o homem como natureza" torna-se uma nova e estranha força geológica, ou melhor: "geohistórica".

Em outro momento, Latour afirmava que, embora a Modernidade tenha sido muitas vezes saudada como o advento do humanismo, tal saudação seria ela própria uma marca da Modernidade, pois no mesmo gesto nascia conjuntamente a "não humanidade" das coisas - dos objetos ou das bestas - e o nascimento de um Deus suprimido. A "constituição moderna" decorreria da organização desses três eixos, que Latour divide entre o que está acima e o que está abaixo, de um lado, e os humanos e não humanos, de outro. Ocorreria com essa separação "aproximadamente o mesmo que ocorre 
com aquela que distingue o judiciário do executivo. Esta última não teria como descrever os múltiplos laços, as influências cruzadas, as negociações contínuas entre os juízes e os políticos" (Latour, 2009, p. 19). Mas, apesar das inconsistências, negar sua separação seria um equívoco:

Da mesma forma como a ideia de Revolução levou os revolucionários a tomarem decisões irreversíveis que não teriam ousado sem ela, a Constituição forneceu aos modernos a audácia de mobilizar coisas e pessoas em uma escala que seria proibitiva sem ela. (...) Este crescimento é, por sua vez, facilitado pela ideia de uma natureza transcendente - contanto que permaneça mobilizável -, pela ideia de uma sociedade livre - contanto que permaneça transcendente - e pela ausência de toda e qualquer divindade - contanto que Deus fale ao coração (Latour, 2009, p. 45-46).

O antropólogo remetia a constituição aos "legisladores" Boyle e Hobbes, fazendo um cruzamento entre laboratório e política, mas - deixando de lado a exata forma como Latour constrói seu argumento - vê-se que essa separação já é patente nos filósofos que melhor sintetizam as ideias modernas, René Descartes e Immanuel Kant. No caso de Descartes (1973), a separação entre res cogitans, a substância pensante, e res extensae, a substância com extensão, revitaliza o dualismo filosófico do platonismo e o dualismo teológico do cristianismo entre corpo e alma. Nesse processo, a natureza tudo que é externo ao humano - torna-se um relógio mecânico de cujas leis o intelecto poderia, usando o método rigoroso, tomar posse. Os animais, por exemplo, não passariam de autômatos regidos por leis físicas sem qualquer interioridade. No caso de Kant, a construção da razão prática, por exemplo, demanda necessariamente a separação entre uma natureza externa regida por leis mecânicas, tal como se via obrigado a reconhecer pelos sucessos da física newtoniana, e a humanidade enquanto espaço de livre-arbítrio. Ao mesmo tempo em que restringe a possibilidade de a ciência alcançar esse domínio ético - que é alcançado diretamente, enquanto coisa em si - pela razão prática, Kant (2002) alça o ser humano à condição de ente especial, provocando a fusão entre humanismo e antropocentrismo.

Desde então, a cisão kantiana vem passando por ataques contínuos que colocam sob suspeita a divisão de trabalho entre humanidades e ciências naturais. A tendência mais forte - constantemente rechaçada por alguns e acolhida por outros - é o naturalismo, corrente que busca reduzir todo âmbito da experiência humana às respectivas conexões físico-químicas e que poderia encontrar representantes, por exemplo, em filósofos como Daniel Dennett ou Paul Churchland ${ }^{1}$. Enquanto o naturalismo acusa as humanidades de um laxismo empírico, defendendo a adoção dos métodos das hard sciences como substitutivos, seu adversário humanismo - de outro lado - rebate afirmando o reducionismo dos rivais, erguendo um domínio propriamente humano instransponível pelos métodos

\footnotetext{
${ }^{1} \mathrm{O}$ que chamamos naturalismo corresponde ao que Maniglier (2007) denomina, a partir de divisão própria, de "cognitivismo". No marco das perspectivas teóricas como de Descola $(2015 ; 2016)$, naturalismo e humanismo não seriam opostos, mas pertenceriam ao mesmo divisor operando a separação entre natureza e cultura, em contraste, por exemplo, com o animismo, o analogismo e o totemismo. No entanto, aqui se trata de uma divisão dentro de uma divisão. Embora se reconheça que humanismo e naturalismo possam fazer parte do mesmo quadrante, trata-se de uma divisão interna no próprio quadrante que separa perspectivas mais fisicalistas, como a de Dennett, da mais espiritualista, como em Agamben. Ver, por exemplo, Latour (2014, p. 33), quando contrasta os obcecados pela "dimensão humana" contra a "naturalização excessiva" como um caso de disputa interna no território que Descola qualifica como simplesmente naturalista.
} 
da biologia ou outras ciências envolvidas. A cesura curricular, assim, manifesta-se no foco linguístico-discursivo das "artes liberais" (liberal arts) e, do outro lado, a proliferação de novas disciplinas, como sociobiologia, economia comportamental e neuroeducação, tendencialmente adotadas pelos departamentos adstritos às ciências naturais para buscar a aplicação dos métodos a áreas sob o influxo das humanidades.

Neste paper, no entanto, dirigimo-nos ao eixo inverso do debate. Um dos principais argumentos ainda de Bruno Latour (2009) em relação à constituição moderna é de que a operação de "purificação" do modernismo oculta a existência da proliferação de híbridos a todo instante. A tecnologia, por exemplo, seria uma demonstração da inconsistência do "Grande Divisor" (natureza/cultura) da constituição moderna. De certo modo, é isso que aparece com a emergência do conceito de Antropoceno. Enquanto a batalha está no campo "humanismo vs. naturalismo", os naturalistas tentam avançar para o campo físico-químico e eliminar toda folk psychology, e os humanistas procuraram preservar um campo simbólico irredutível que seria propriamente humano (Bensusan, 2017, p. 45-48). Assim, a cultura funciona como blindagem contra o avanço da natureza. No caso do Antropoceno, a relação é invertida: é a cultura - entendida como "atividade humana" - que invade a natureza (como natura naturans), promovendo uma alteração tão substantiva que desfaz a própria fronteira que antes as separava (Hache, 2014, p. 15). Não é a cultura que se naturaliza, mas a natureza que se culturaliza. Não se trata, evidentemente, de transformar a natureza em uma projeção simbólica da cultura, ou reduzi-la a uma representação sem lastro material (ignorado ou suspenso nas aspas fenomenológicas ${ }^{2}$ ), pois isso seria simplesmente repetir, pela via invertida, o mesmo dualismo. Trata-se de generalizar com diferenciações os atributos antes restritos à cultura, como a mutabilidade, a criação, o conexionismo e o dinamismo. Por isso, Derrida (1967, p. 63) chegava a cogitar simplesmente "demitir" os conceitos de natureza e cultura.

Ou seja, se o conceito de Antropoceno é válido, também pelo outro lado que o Grande Divisor naufraga. Não é a natureza (dos naturalistas) que ameaça a cultura, supostamente reduzindo o ser humano a um mero autômato determinado pelas suas conexões neurais ou pelo código genético. No Antropoceno, é a cultura (antrópica) que invade a natureza, desnaturalizando o que antes estava para lá da borda externa do constituição moderna. Note-se, contudo, que estamos tomando apenas momentânea e retoricamente a divisão como verdadeira para, a partir da sua própria inconsistência interna, percebê-la como variação de um hibridismo irredutível, já que a separação constitucional nubla a percepção do que significa o Antropoceno. Ao mesmo tempo em que o divisor cai pela óbvia interferência antrópica no que se denominava "natureza", zona separada do antigo "construtivismo social", a invasão das inundações, da erosão e da bioquímica no universo humanista reconfigura o que significa o anthropos, colocando sua atividade em ação em regiões que ultrapassam as formas antigas do naturalismo (Latour, 2014, p. 32-33).

Assim, o próprio conceito - muito típico das humanidades e ciências sociais - de desnaturalização, que envolve também uma operação política

\footnotetext{
${ }^{2}$ Sobre o tema, ver Valentim (2018).
} 
de denúncia de práticas violentas incorporadas ao habitus social, acaba revelando-se em parte devedor da "Grande Divisão", na medida em que externaliza a natureza separando-a do mundo humano. Implicitamente, tal argumento carrega o sentido de que o natural é estático, repetitivo e imutável, enquanto o cultural seria dinâmico, criativo e variável. A percepção da "naturalização" — confundida com a reificação e em contraste com a "convenção" da linguagem e do simbólico - demonstra um humanismo de fundo que continua dividindo antropocentricamente os agentes sociais. Com o Antropoceno, no entanto, o próprio natural se "desnaturaliza", passando a tornar-se parte de uma mesma ambiência dinâmica e criativa além do humano. Por isso, Danowski e Viveiros de Castro podem afirmar, para a compreensível perplexidade de alguns, que

Quem está do 'outro lado', isto é, quem se pretende fora da superfície única humanidade-mundo, é que se vê imbuído da missão de cortar essa banda de Möebius com a tesoura modernista da 'vocação des-naturalizante da humanidade' - são estes os inimigos. O problema, já o vimos, é que tais inimigos se acham, pelo menos no que concerne aos bons velhos modos de ordenar o espectro político, tanto à esquerda quanto à direita (Danowski \& Viveiros de Castro, 2014, p. 147).

Com isso, abre-se todo um flanco de abordagens renovadas de construções que antes eram descritas sob a luz da constituição moderna. É o que Gilles Deleuze e Félix Guattari, por exemplo, já detectavam ao transformar a "genealogia da moral" nietzschiana - depois levada a novas patamares por Michel Foucault - em "geologia da moral". Esforço que depois Guattari, inspirado em Gregory Bateson, levou a cabo como "três ecologias", ligando natureza, sociedade e psiquismo (Stengers, 2014, p. 151). Esses trabalhos poderiam compor o que, na belíssima expressão de Manoel de Barros retomada por Hilan Bensusan, é chamado de "gramática expositiva do chão", onde "é o chão - e o chão de um organismo é sua pele - que articula duplamente sua interioridade que faz fisicalidade e uma fisicalidade que faz interioridade". Por isso, "não há uma fisicalidade independente da interioridade, mas nem tampouco uma interioridade que não precise ser patrocinada por fisicalidades" (Bensusan, 2017, p. 79). Essa estrutura de dupla articulação a pele do chão - é o que permite reconectar áreas separadas por uma rigorosa divisão de trabalho na Modernidade, introduzindo uma nova perspectiva transdisciplinar.

Trata-se aqui de apenas introduzir a temáticasem buscar resolver suas principais questões - para públicos que porventura possam ainda não estar devidamente familiarizados, dadas as múltiplas resistências que esse tipo de disrupção pode produzir. A literatura sobre o tema é amplíssima e já possui uma parte pequena traduzida, ou em vias de tradução ou publicação, para o português. Sob diferentes enfoques e muitas variantes (ecofeminista, multinaturalista, multiespécies, marxista, etc.), há dezenas de obras-referência, como Mitchell (2011), Danowski \& Viveiros de Castro (2014), Hache (2014), Moore (2015), Bonneuil \& Fressoz (2016), Haraway (2016), Latour (2017), Tsing et al. (2017) e Valentim (2018), entre muitos outros e outras, debatendo inclusive a nomenclatura (Antropoceno, Capitaloceno, Cthuluceno, Plantationceno, etc.), seu marco inicial e suas consequências políticas, epistemológicas e ontológicas. A abordagem específica de cada uma dessas variantes, entretanto, excederia as possibilidades do presente texto, que tem finalidade 
meramente introdutória, como espécie de convite, e apresenta como ponto central exemplos ainda não familiares ao público brasileiro do estilo de problematização que o choque do Antropoceno coloca.

Para tanto, apresenta-se dois casos de transformações recíprocas entre história e ecologia causadas pelo acontecimento Antropoceno - Bonneuil e Moore - apontando para uma nova transdisciplinaridade que ignora as divisões mais fundamentais da constituição moderna para, ao final, tentar extrair implicações desses deslocamentos. Não se pretende resumir todo esforço teórico dos trabalhos e muito menos esgotar os tópicos mencionados, mas apenas mostrá-los como ferramentas heurísticas que nos permitam pensar para além do dualismo epistemológico que traçou a fronteira entre humanidades e ciências da natureza da constituição moderna a partir do evento Antropoceno. No primeiro caso, com os historiadores franceses Bonneuil, Fressoz \& Jouvancourt, trata-se de criticar uma visão ingênua da crise ecológica, em geral atribuída aos efeitos da Revolução Industrial cumulados com a cegueira humana sobre as respectivas consequências. Assim, é a história que transforma a ecologia, substituindo uma visão excessivamente simplória da narrativa acerca da chegada no Antropoceno por uma elaboração crítica que expõe as decisões políticas, repressões e opções que nos trouxeram até aqui. Em Jason Moore (2015), por outro lado, o conceito de Antropoceno é substituído pelo Capitaloceno. No entanto, criticando o framework dualista de herança cartesiana que a área se acostumou a reproduzir, inclusive nos seus melhores casos, os estudos "marxistas verdes" (materialismo histórico), Moore produz o efeito de uma ecologia que transforma a história.
Os dois enunciados — história que transforma ecologia (Bonneuil) e ecologia que transforma a história (Moore) — podem ser entendidos no paralelismo espelhado que toma as palavras tanto como organização material do mundo (a história como fluxo de tempo, a ecologia como rede de relações materiais entre entes) quanto como disciplinas científicas com seus respectivos modelos epistemológicos. A dupla transformação (história/ ecologia e ecologia/história) é característica do choque anunciado e aponta, entre outras muitas implicações, para um novo currículo em que as célebres divisões modernas, elas próprias corresponsáveis pelo problema Antropoceno, perdem espaço.

\section{Para entender a história do Antropoceno}

Christophe Bonneuil \& Jean-Baptiste Fressoz começam sua obra "O Acontecimento Antropoceno" ("L'evénement Anthropocène") anunciando o Antropoceno como nossa época. Segundo os historiadores da ciência, estaríamos nos transferindo de um longo período nomeado Holoceno para uma nova época em que a humanidade figura como uma força geológica maior. Mas a pergunta da qual parte o livro é: como chegamos até aqui? Responder a essa questão não é apenas um desafio teórico típico dos historiadores, pois envolve também a própria natureza das respostas que serão dadas ao problema. A narrativa oficial do Antropoceno, segundo os autores, é que nós, a espécie de humana, inconscientemente destruímos a natureza ao ponto de colocar o sistema-Terra em uma nova era geológica. No final do século XX, finalmente os cientistas teriam aberto nossos olhos produzindo uma reflexão sobre os impactos destrutivos das nossas atividades. 
Ainda segundo esse discurso, agora sabemos e, por isso, podemos ter consciência das consequências dos nossos atos e tomar as providências cabíveis (Bonneiul \& Jouvancourt, 2014, p. 57-66, 74-76 e 86-91; Bonneuil \& Fressoz, 201633).

É precisamente essa narrativa que os historiadores citados buscam confrontar. Não porque neguem a existência do acontecimento Antropoceno ou suas consequências drásticas e radicais para a configuração das sociedades humanas. Mas porque não se trata de uma história tão simples. Para chegarmos até o momento atual, foi necessário um progressivo silenciamento das vozes dissidentes que alertavam e lutavam contra os perigos inerentes ao desenvolvimento industrial (Bonneuil \& Jouvancout, 2014, p. 67). Seguindo uma tradição que poderíamos remeter a Walter Benjamin, Bonneuil $\&$ Fressoz contam, ao longo do livro, quem foram essas "vozes emudecidas" dos "vencidos da história" do Antropoceno.

Os historiadores, para tanto, promovem uma desconstrução da "grande narrativa geocrática do Antropoceno", isto é, dessa visão não histórica e ingênua da construção do status quo. Contam, para isso, sete histórias reprimidas pela narrativa científica: a) termoceno; b) thanatoceno; c) fagoceno; d) phronoceno; e) agnotoceno; f) capitaloceno e g) polemoceno. Elas envolvem retomar genealogicamente os conflitos que envolveram a constituição do nosso estágio atual em torno à condição térmica, mortal, alimentar, discursiva, epistemológica, econômica e política. Apresenta-se, em seguida, uma breve descrição de cada.
O termoceno envolve a história política do $\mathrm{CO}_{2}$. Para tanto, confrontam a leitura das transições energéticas, nas quais teríamos passado da madeira ao carvão, do carvão ao petróleo e, então, do petróleo à energia nuclear. A história da energia não é constituída de transições, mas de adições, isto é, sucessivas camadas de extração foram sendo acrescentadas enquanto fontes de energia prismática. O termo "crise energética" - que legitimaria o discurso das transições - foi a rigor inventado por think tanks e popularizado por instituições poderosas entre 1975 e 1980 para justificar a utilização dos "combustíveis alternativos", especialmente o nuclear. Falar em transição em vez de crise, dizem Bonneuil e Fressoz, tornaria o futuro menos propenso à ansiedade em relação ao esgotamento das fontes de energia convencionais, vinculando-o a um planejamento gerencial eficaz segundo uma racionalidade tecnocrática. $\mathrm{O}$ conceito de transição, no entanto, subestimaria o papel dos sistemas antigos e superestimaria os determinantes tecnológicos em detrimento da arbitragem econômica (Bonneuil \& Jouvancout, 2014, p. 68; Bonneuil \& Fressoz, 2016).

A história das emissões de $\mathrm{CO}_{2}$, segundo os autores, esconderia uma longa investigação sobre a ineficiência da queima de combustíveis fósseis para os fins buscados e a naturalização da forma buscada de energia em detrimento de alternativas. O recurso ao petróleo e ao gás não seriam decisões inevitáveis, mas escolhas militares e ideológicas que os historiadores deveriam analisar. Retomar o contexto da decisão significa também abrir campo para que potencialidades que foram desperdiçadas

\footnotetext{
${ }^{3}$ Uma vez que consultada a edição Kindle, não foi possível assinalar quais as páginas específicas do livro, uma vez que a própria noção de "posição" do reader pode variar conforme o tamanho que o usuário elege.
} 
à época, em nome do rumo tomado, possam ser reavaliadas. O investimento em energia solar, por exemplo, foi derrotado em 1950 nos Estados Unidos com o desenvolvimento de subúrbios, promoção de casas pré-fabricadas de baixo custo e um marketing agressivo das companhias de energia elétrica. Não havia, portanto, necessidade direta do rumo adotado: ele foi reflexo de escolhas, como as campanhas publicitárias e governamentais por carros individuais, que desprezaram opções em detrimento de outras, em especial em relação à queima de $\mathrm{CO}_{2}$. Chama atenção, nesse sentido, o papel dos países anglo - Estados Unidos e Grã-Bretanha - na constituição dessa forma de vida, a ponto de os autores ironizarem que "o Antropoceno é um Angloceno" (Bonneuil \& Jouvancout, 2014, p. 71-73; Bonneuil \& Fressoz, 2016).

O thanatoceno envolve o papel das guerras e do ecocídio na constituição do Antropoceno. Os avanços em produtividade e destrutividade caminharam lado a lado, tornando as tecnologias militares, por exemplo, mais baratas. Os estados ricos passaram a ter gigantescos complexos industriais de guerra, tornando os sistemas de industrialização integrados aos modelos de pesquisa e desenvolvimento. Esses processos envolveram inclusive manipulação dos próprios sistemas naturais, tornando necessário que a ONU intervisse para proibir, por exemplo, a manipulação da atmosfera para fins militares. Bonneuil e Fressoz ainda demonstram como as metáforas remetem ao ecocídio, como quando Churchill explica o sentido da guerra afirmando que "tornaria a Alemanha um deserto" (Bonneuil \& Fressoz, 2016). A "necropolítica" que Mbembe investigou, na qual há uma "instrumentalização generalizada da existência humana e destruição material de corpos humanos e populações", torna-se um dos eixos a partir dos quais se constrói o Antropoceno (Mbembe, 2018, p. 10-11).

O fagoceno envolve a construção da sociedade de consumo. Nos anos 1970, o então Presidente dos Estados Unidos Jimmy Carter afirmara que "a identidade humana não é mais definida pelo que alguém faz, para pelo que se tem" e procurara retomar, diante do choque do petróleo, o "espírito americano" que renasceria em relação ao individualismo consumista. A derrota eleitoral de Carter para Ronald Reagan em 1980 ilustra a importância que o consumo adquire na esfera pública. O consumismo, investigado por inúmeros trabalhos de peso - de Herbert Marcuse a Christopher Lasch - transforma-se no eixo central das sociedades ocidentais a partir dos anos 50 e o próprio medidor da felicidade nos países centrais. A transformação da natureza em mercadorias teria tornado mais fácil sua circulação no capitalismo global e, com isso, formas alternativas de distribuição - como a troca e a negociação - acabam sendo substituídas pela oferta de crédito e criação do circuito consumista. Finalmente, os historiadores demonstram como a publicidade muda para produzir o sentimento de insatisfação no consumidor, sempre em falta em relação aos seus desejos e incapaz de considerar suficiente seu modo de vida, produzindo o que nomeiam de "hedonismo disciplinar" (Bonneuil \& Fressoz, 2016).

Além disso, o fagoceno também envolve a opção pela obsolescência programada que hoje é central na sociedade de consumo, afetando profundamente o ciclo de materiais. As transformações urbanas, com a expansão das cidades e a água encanada, e os fatores tecnológicos, como a manufatura do papel, teriam dificultado e jogado numa profunda crise a economia da reciclagem que ainda existia no 
século XIX. Com isso, desenvolve-se uma cultura do "jogar fora", somada à obsolescência psicológica como foram de evitar os riscos da sobreprodução. Como também, de resto, a própria ideia de crescimento econômico infinito é naturalizada (Bonneuil \& Fressoz, 2016).

O "phronoceno" envolveria a dimensão da gramática da reflexividade ambiental. Raramente, segundo os autores, a história se dedicaria a examinar os conflitos ecológicos, removendo-os da história política em detrimento de outros conceitos. Assim, haveria caminho para a "surpresa" em torno às consequências do modelo assumido. No entanto, os autores mostram que os construtores da história moderna teriam se interessado, no início, pelo papel do ambiente sobre as sociedades e os indivíduos, assim como das inovações tecnológicas sobre a natureza, inclusive propondo, como fazia Buffon, uma "paz universal" entre humanidade e natureza. Inicialmente, isso pressupunha a "transformação racional" do meio ambiente, abrindo caminho para uma livre intervenção. Excepcionalmente, contudo, pensadores como Haeckel, Lineu, Thoreau, entre outros, teriam se debruçado sobre as relações sistêmicas entre humanidade e natureza. Em 1919, o arquiteto alemão Leberech Migge, por exemplo, usa pela primeira vez o termo "verde" em sentido político no seu "Das grüne Manifest", no qual desenvolve a concepção de cidades jardinadas que seriam autossuficientes graças à energia solar $\mathrm{e}$ eólica, horticultura e reciclagem de resíduos orgânicos. Hoje em dia, esses pensamentos sobrevivem desde o relatório do Clube de Roma até as teorias do decrescimento (Bonneuil \& Jouvancout, 2014, p. 76-80; Bonneuil \& Fressoz, 2016).

Tudo isso teria sido impossível sem o agnotoceno. Segundo os autores, a agnotologia consiste na investigação em torno à produção de zonas de ignorância. $\mathrm{O}$ Antropoceno não teria sido viável senão com a confluência entre a mercantilização do humano e da natureza somada à desqualificação da crítica ambiental e a denegação da finitude da Terra. A economia política, em particular, contribuiu para forjar, em paralelo ao homo economicus, o mundus economicus, que basicamente seria a correspondência paralelista entre uma natureza que coubesse nos esquemas do liberalismo e que a indústria pudesse mobilizar. O gerenciamento matemático aparece como uma promessa que quer dar conta das ditas "fragilidades das florestas", por exemplo, permitindo a exploração do carvão e dos combustíveis fósseis em geral. Ao externalizar a natureza com sua teodiceia do crescimento infinito, a economia política produz uma ampla desmaterialização, concebendo todos os movimentos como fluxos financeiros abstratos. Tudo isso teria se agravado com a conversão do capitalismo industrial em capitalismo financeiro. Afirmam:

\begin{abstract}
No início do século XIX, a modernidade industrial construiu a idéia da natureza como estoque, externo à economia e constituindo um armazém inesgotável. No final do século XX, uma nova fase do capitalismo - financeira, pós-moderna, flexível e baseada em rede - veio e desafiou essa ontologia industrial moderna da natureza. No novo espírito do capitalismo tardio, a questão da valorização da diversidade substitui a questão mais antiga de reduzir a diversidade para padronizar a produção, os fluxos agora importam tanto quanto estoques, serviços tanto quanto produção material, relacionamentos tanto quanto entidades (Bonneuil \& Fressoz, 2016, tradução livre).
\end{abstract}

Da mesma forma, o marxismo dominante focando na teoria do valor e da distribuição do produto entre duas classes, trabalhadores e capita- 
listas, essencialmente veria apenas dois fatores de produção: capital e trabalho. Apesar de a teoria da Terra como metabolismo em Marx e Engels (que veremos melhor no próximo item), a ciência econômica marxista costuma recalcar a questão energética sob a acusação de malthusianismo (Bonneuil \& Fressoz, 2016).

O capitaloceno, por sua vez, é a "história combinada do sistema-Terra com os sistemas-mundo". O capitalismo tornou-se coextensivo à Terra. A dinâmica do capital produziu, assim, espécie de "segunda natureza" feita de estradas, plantations, pistas, minas, gasodutos, estações de energia, futuros mercados e navios-contêineres, ou seja, tudo uma "tecnoestrutura orientada ao lucro". As teorias do sistema-mundo (que, como veremos, são retomadas por Moore) agora são atualizadas pela entrada da pegada ecológica e termodinâmica e pelos fluxos de matéria e energia que acarretam uma distribuição desigual de entropia ao longo da Terra. Além disso, segundo os autores, o sucesso econômico dos países ocidentais industrializados não teria sido possível sem a troca desigual que envolve, por exemplo, a queima de combustíveis fósseis e a externalização dos problemas ambientais decorrentes (Bonneuil \& Fressoz, 2016).

Finalmente, o polemoceno consiste em recolher as histórias das resistências à deterioração da Terra desde 1750. Para tanto, os historiadores narram as inúmeras lutas em defesa das florestas e o direito ao seu uso desde a Revolução Francesa, passando pela questionamento das máquinas e da produção em massa, a oposição às inovações e à colonização, terminando, enfim, mostrando o questionamento da sociedade industrial e a Grande Aceleração dos anos 1960 em diante (Bonneuil \& Fressoz, 2016).
Em síntese de todas essas dimensões, afirmam:

A história que propusemos pode parecer deprimente, ou seja, que nossos ancestrais desestabilizaram a Terra e seus ecossistemas, apesar de saberem o que estavam fazendo. Como não houve uma transição da inconsciência para a conscientização, uma vez que o atual capitalismo financeirizado tem suas próprias formas de desinibição, tudo nos leva a temer que as coisas continuem como estão até agora ... Mas abandonar a narrativa oficial de um despertar permite um diálogo mais lúcido e frutífero com as advertências dos cientistas do sistema Terra. Também tivemos várias histórias do antropoceno que nos convidam a conceber em termos políticos os metabolismos da energia e da matéria comandados por esses mecanismos - de produção, troca e consumo - que foram inventados e impostos por grupos, imaginários e instituições bastante particulares, e em circunstâncias específicas. Essas histórias nos convidam a tomar um controle político sobre as instituições e oligarquias, os poderosos sistemas simbólicos e materiais que nos levaram ao Antropoceno: aparatos militares, sistema de desejo consumista e infraestrutura, lacunas de renda e riqueza, gigantes da energia e os interesses financeiros da globalização, os aparatos tecnocientíficos quando atuam na lógica das mercadorias ou silenciam críticas e alternativas (Bonneuil \& Fressoz, 2016, tradução livre).

A partir das múltiplas dimensões do Antropoceno, a história interfere diretamente na narrativa das ciências, produzindo o efeito de revelar a contingência das configurações atuais diante de alternativas que se colocaram no caminho do triunfante progresso ocidental, cuja linearidade não tem nada de natural no sentido que seus defensores, ingênua ou maquiavelicamente, costumam sustentar. 


\section{Jason Moore: o capitalismo nas redes da vida}

Moore começa seu trabalho colocando-se entre dois territórios: de um lado, a crítica marxista da economia política e os estudos de formação do capitalismo, tendo como exemplo I. Wallerstein, F. Braudel e G. Arrighi; de outro, os estudos "verdes" sobre o impacto das atividades humanas sobre a Terra. Moore tem consciência que não é o primeiro a tentar interconectar essas dimensões - tendo John Bellamy Foster e o próprio David Harvey, por exemplo, como paradigmas -, mas traça ao mesmo tempo uma crítica ao cartesianismo subjacente a ambas perspectivas, que ainda separariam natureza e sociedade de modo residual ${ }^{4}$. Para dar conta do problema, necessário eliminar o aspecto aditivo com que os fatores costumam vir juntos: natureza mais sociedade, economia mais ambiente. O próprio imaginário de uma crise convergente seria ilusório, pois se trata da mesma crise desde uma perspectiva capaz de ultrapassar o dualismo. A ideia de que o capitalismo agride o meio ambiente, por exemplo, pressupõe um fundo natural imutável. A natureza, ao contrário, está em permanente transformação e, por isso, não podemos simplesmente colocá-la como externalidade, tal como tanto a economia política neoclássica quanto o marxismo fariam. $\mathrm{O}$ capitalismo, assim, "é um caminho de organização da natureza" (Moore, 2015, p. 2).

A estrutura proposta por Moore em contraponto ao dualismo é de uma "dupla internalidade". O capitalismo é, ele próprio, uma variação histórica do arranjo entre humanos e não humanos. Seus efeitos não se contrapõem a um fundo eterno e invariável. O dualismo erraria por substantivar os dois termos, sociedade e natureza. Moore, em contraponto, procura estabelecer uma economia relacional entre eles. Só existem, a rigor, modalidades dessas relações. Com isso, a ultrapassagem ocorre por meio da ideia do oikeios. Segundo Moore, "oikeios é uma maneira de nomear a criativa, dialética e histórica relação entre e por dentro de naturezas humanas e extrahumanas" (Moore, 2015, p. 35). A natureza não é um fator adicional colocada ao lado da cultura ou da sociedade. Ela "torna-se a matriz na qual a atividade humana se desdobra, e o campo no qual a agência histórica opera (...). Da perspectiva do oikeios, civilizações não 'interagem' com a natureza como recurso (ou como lata de lixo); elas desenvolvem-se por meio da natureza-como-matriz" (Moore, 2015, p. 36).

Com isso, Moore estabelece um novo equilíbrio entre o processo de exploração do trabalho, típico da leitura histórica marxista, e a construção da "natureza barata" (cheap nature). Os marxistas verdes dariam um significativo destaque para a Lei do Valor, que se estabelece mediante a produtividade do trabalho em relação à produção de mercadorias. A Lei do Valor não é uma lei de ferro determinística, mas um padrão durável de poder e produção que se estabeleceu no tempo e espaço do capitalismo instituindo o trabalho abstrato. Porém a Lei do Valor acabaria deixando de lado que a natureza também contribuiria para a formação do capitalismo. Fazendo um paralelo interessante com os estudos feministas, Moore realça que o marxismo teria invisibilizado outro campo de trabalho: no caso

\footnotetext{
${ }^{4} \mathrm{Na}$ mesma chave do Capitaloceno, temos estudos como os de Mitchell (2011), Frase (2016) e Malm (2016). Um pequeno ensaio de Malm, O Mito do Antropoceno, foi traduzido para o português pela revista Piseagrama (2015).
} 
das feministas, o trabalho reprodutivo e doméstico; no caso dos verdes, o próprio ambiente natural (Moore, 2015, p. 52). Assim, sem uma "natureza barata", a própria acumulação acabaria encontrando muito antes os impasses que vive hoje. Ao lado da exploração do trabalho, os ciclos de crescimento econômico estariam diretamente vinculados à capacidade de se apropriar de trabalho/energia não pagos. A mais-valia do trabalho seria complementada pela construção dos Quatro Baratos (Four Cheaps), núcleo da mais-valia mundo-ecológica (world-ecological surplus) (Moore, 2015, p. 95-96).

O capitalismo seria baseado em Quatro Baratos: comida, força de trabalho, energia e matéria-prima. Moore dedica-se, então, a mostrar como cada um corresponde a um ponto específico da organização do oikeios tal como o capitalismo o distribui. Contra as imagens que visualizam a natureza como algo que "dá limite" à atividade humana, Moore busca integrar a atividade humana como natureza, já que a rigor não existe algo essencialmente natural - a natureza é histórica (Moore, 2015, p. 115). O dualismo passa, com isso, a uma dialética. Assim como Marx teria mostrado que não há capitalismo sem trabalho não pago (exploração), as feministas demonstrado a lacuna na teoria marxista (com o privilégio operário sobre o trabalho reprodutivo), $\mathrm{o}$ terceiro passo seria integrar a teoria do valor em um framework que ultrapasse o dualismo, percebendo que também há uma exploração da Natureza Barata. Como Marx já descrevera em "O Capital", o problema da formação do valor está ligado à exaustão, processo que ele próprio associara - fazendo a mediação pelo conceito de metabolismo - com a própria terra.

Há, portanto, um deslocamento epistemológico da história do campo simbólico, no qual preponderam as redes intra-humanas, para o ecológico, no qual a reprodução do capital torna-se um processo material formado a partir de dois pivôs: a reprodução biofísica, formada por força de trabalho, florestamento e agricultura; e a extração geológica visando à obtenção de energia e aos minerais (Moore, 2015, p. 146). Para o autor, viveríamos por isso não em um "Antropoceno", como Crutzen e os geólogos estariam propondo, mas em um "Capitaloceno". A ideia de Antropoceno se manteria antropocêntrica, colocando os humanos fora da natureza. Na medida em que os sistemas naturais e sociais humanos estão coimplicados numa dialética relacional que evita a própria cisão, suturando-a enquanto oikeios, podemos visualizar a particularidade do capitalismo enquanto extração não paga de energia (carvão, por exemplo), transformando-a em capital, ao contrário da representação que estabelece a Revolução Industrial como marco da era do humano como força geológica (Moore, 2015, p. 180). O Capitaloceno - construído ao longo de séculos de formação de uma ecologia-mundo (world ecology) - teria se construído pela dupla que envolvia a proliferação dos conhecimentos e regimes simbólicos que concebiam a natureza como externalidade, o espaço como plano e o tempo como linearidade, somado a uma nova configuração da exploração (da força de trabalho) e da apropriação (na mais-valia ecológica $)^{5}$.

\footnotetext{
${ }^{5}$ Para uma crítica à tese do Capitaloceno, conferir, por exemplo, o seminal texto de Chakrabarty, um dos primeiros a ser traduzido para o português sobre a temática, publicado em Sopro (2013). Ver também Haraway (2016).
} 


\section{Considerações finais: do Grande Divisor à Era das Geohumanidades}

O acontecimento Antropoceno provoca uma reviravolta nas humanidades e nos respectivos currículos. A distribuição da constituição moderna é abalada por dentro, reunindo sobre o mesmo plano o natural e o artifício. Assim, tanto a apresentação simplificada dos cientistas acerca dos fatos sociais, criticada por Bonneuil e outros (2016), quanto a desconexão entre o cultural e o natural, rebatida por Moore (2015), desfazem-se no mesmo ato. Os sistemas humanos passam a fazer parte de um mesmo contexto no qual não apenas interagem como bolhas dentro de bolhas cujo atrito somente se faria sentir perifericamente, mas os componentes "naturais" passam agora a fazer parte imanente dos arranjos humanos. Como a descrição do Capitaloceno de Moore demonstra, a própria divisão de materiais, assim, perturba-se, e conceitos como de exploração, por exemplo, passam a ser aplicados a campos alheios ao humano.

Velhos problemas como, por exemplo, a questão em torno do dado e do construído, que ainda hoje fazem parte da paisagem das humanidades, tornam-se sem sentido. O dado nada mais é do que a reificação do construído em qualquer instância, como o efeito Antropoceno - a transformação da paisagem extra-humana pela cultura humana - demonstra. $\mathrm{O}$ construído, por outro lado, perde o sentido fraco e torna-se, por isso, motivo para ser tomado a sério. Se o que existe é em alguma medida construído - e essa construção é humana e extra-humana e nada tem a ver com o mental ou o representacional então é necessário reconsiderar o peso morto que o convencionalismo generalizado pós-modernista deu à construção. Falar em contingência não implica chancelar imediatamente sua destruição. O próprio sistema-Terra é exemplo disso. Sua rápida transformação a partir da "Grande Aceleração" não envolve nenhuma promessa de redenção ou futuro: uma vez desestabilizado o equilíbrio termodinâmico do planeta, as próprias condições de possibilidade que nos levaram a pensar podem desaparecer (Latour, 2014, p. 47). Também a distribuição de tarefas entre uma natureza estática, intangível e idêntica a si mesma desaparece na mesma medida em que os sistemas culturais hiperdinâmicos, leves como uma pluma no paradigma da linguagem, passam a receber seu peso material correspondente. Da imagem do "espaço sem gravidade" da epistemologia cuja missão seria inspecionar uma esfera transparente desde um "lugar nenhum" por um corpo desencarnado passa-se a uma restauração do "campo gravitacional" do pensamento (Latour, 2014, p. 49-50).

$\mathrm{E}$, diante desses avanços, novos problemas aparecem - dos quais se dá apenas notícia aqui. A disputa entre pós-modernismo multiculturalista e modernismo universalista - típica, por exemplo, do duelo filosófico entre Lyotard, Rorty e Habermas - reconfigura-se em múltiplas outras versões a partir do choque entre ontologias, como ocorre com o mononaturalismo e o multinaturalismo (Hache, 2014, p. 19; Bensusan, 2017, p. 108-109). Dentre os próprios modelos desenvolvidos no texto, pode-se perceber uma tensão entre uma concepção radicalmente imanentista dos oikeius de Moore (2015) e outra, mais inspirada nos trabalhos de Isabelle Stengers, em torno à intrusão de Gaia (Stengers, 2014, p. 148). Segundo a filósofa belga, Gaia seria um tipo de transcendência, porém de modo totalmente distinto que o "ponto de vista de lugar nenhum": 
Gaia, a que faz intrusão, não nos pede nada, sequer uma resposta para a questão que impõe. Ofendida, Gaia é indiferente à pergunta "quem é o responsável?" e não age como justiceira - parece que as primeiras regiões da Terra a serem atingidas serão as mais pobres do planeta, sem falar de todos esses viventes que não têm nada a ver com a questão. $\mathrm{O}$ que não justifica, de modo algum, uma indiferença qualquer em relação às ameaças que pesam sobre os viventes que habitam conosco essa Terra. Simplesmente, não é da conta de Gaia (...) Gaia é o nome de uma forma inédita, ou não esquecida, de transcendência: uma transcendência desprovida das altas qualidades que permitiriam invocá-la como árbitro, garantia ou recurso; um suscetível agenciamento de forças indiferentes aos nossos pensamentos e aos nossos projetos (Stengers, 2015, p. 40-41) ${ }^{6}$.

Da mesma forma, as consequências politicas do choque do Antropoceno parecem inevitáveis. Pode-se, por um lado, considerar - como faz Bruno Latour - que a polarização em torno à negação do problema ecológico é, ela própria, constitutiva dos feixes que dividem o cenário político. Assim, Latour afirma que as elites oligárquicas mundiais, percebendo o risco que o colapso ambiental representa, teriam tomado precauções para evitar que tais questões sejam levadas à esfera pública, investindo no discurso negacionista como forma de permanecer indene às transformações necessárias e controlar seu impulso de modo que não interfira na divisão de poder mundial (Latour, 2017). Mesmo entre os que não denegam os problemas climáticos, a questão ainda se divide entre os que defendem o aprofundamento do fundo prometeico da nossa cultura, buscando controlar a natureza por meio de geoengenharia e outras estratégias tecnológicas, e os que consideram que só uma transformação no nosso modo de existência - inspirando-se em outras formas por meio da experiência decolonial - poderia abrir possibilidades de escapar do colapso iminente (Bonneuil \& Jouvancourt, 2014, p. 98-102; Danowski \& Viveiros de Castro, 2014; Hache, 2014, p. 23).

Tem-se, assim, um novo paradigma transdisciplinar para as humanidades, agora convertidas em geohumanidades. Não se trata apenas de inserir o que tradicionalmente se denomina geopolítica no contexto das ciências humanas, mas de compreender o geo no sentido mais forte, ainda mais forte do que muitos historiadores e teóricos do espaço já haviam trazido. Se a noção de ambiência tornou-se constitutiva para pensar o espaço humano, é preciso ainda ultrapassar a dimensão fenomenológica - ainda situada no âmbito do simbólico e da linguagem - e arriscar-se na confluência com a natureza como tal, em contato com a forma como os cientistas naturais vêm desenvolvendo. O Grande Divisor torna-se uma fronteira porosa cuja própria existência é cada vez menos justificada. Os conceitos, de certo modo, passam por uma desconstrução cujo impacto exige um redesenho. Os currículos precisam adaptar-se a essa transformação que perturba divisões departamentais, distribuições de laboratórios e monopólios metodológicos. Se desconstruir não é destruir, mas

\footnotetext{
${ }^{6}$ A disputa entre universalismo kantiano ou neokantiano ocupou grande parte do imaginário das humanidades na segunda metade do século XX, colocando em choque livros com A Condição Pós-Moderna, de Jean-François Lyotard, e O Discurso Filosófico da Modernidade, de Jürgen Habermas, e entre eles uma centena de problematizações por campos inteiros, como os estudos culturais, a filosofia política e a antropologia, ainda que - comparando à temática aqui desenvolvida - perceba-se que sempre se estava no interior da sociedade humana, enquanto aqui trata-se de extrapolar para novos quadrantes. A tensão entre a visão imanentista de Moore e a transcendência de Gaia em Stengers, cuja explicitação inclusive é bastante difícil, exigiria outro texto específico, dada a complexidade da questão. Mencionam-se as questões apenas como convite.
} 
dar um novo fundo e uma nova forma, é possível que o arcabouço conceitual que dá base ao currículo construído a partir da constituição moderna, hoje, precise ser totalmente reconstruído para dar conta do acontecimento Antropoceno e da intrusão de Gaia.

\section{Referências}

Bensusan, H. Linhas de animismo futuro. Brasília: IEB Mil Folhas, 2017.

Bonneuil, C.; Fressoz, J-B. The Shock of the Anthropocene. Trad. David Fernbach. London/New York: Verso Books, 2016 (edição Kindle).

Bonneuil, C; Jouvancourt, P. de. En finir avec l’Épopée. Récit, géopouvoir et sujets de l'Anthropocene. In: Hache, É. (Org.). De L'Univers Clos au Monde Infini. Paris: Éditions Dehors, 2014. p. 57-105.

Chakrabarty, D. O clima da história: quatro teses. Trad. Denise Bottman, Fernanda Ligocky, Diego Ambrosini, Pedro Novaes, Cristiano Rodrigues, Lucas Santos, Regina Félix e Leandro Durazzo. Coordenação e Revisão: Idelber Avelar. Sopro, 91, 2-22, 2013. Disponível em: http://www. culturaebarbarie.org/sopro/n91s.pdf

Crutzen, P. The ,Anthropocene'. In: Ehlers, E.; Krafft, T. (Eds.). Earth System Science in the Anthropocene. New York: Library of Congress, 2005. p.13-18.

Danowski, D.; Viveiros de Castro, E. Há mundo por vir? Ensaio sobre os medos e os fins. Desterro: ISA/Cultura e Barbárie, 2014.

Descartes, R. Meditações. In: Descartes, R. Os Pensadores. Trad. Jaime Guinsburg; Bento Prado Jr. São Paulo: Abril Cultural, 1973. p. 93-150.

Descola, P. Outras Naturezas, Outras Culturas. Trad. Cecília Ciscato. Rio de Janeiro: Editora 34, 2016.

Descola, P. Além de natureza e cultura. Tessituras, 3(1), 7-33, 2015.
Derrida, J. De la Grammatologie. Paris: Éditions de Minuit, 1967.

Frase, P. Four futures: life after capitalism. London/New York: Verso, 2016.

Hache, É. Introduction: Retour sur Terre. In: Hache, É. (Org.). De L'Univers Clos au Monde Infini. Paris: Éditions Dehors, 2014. p. 11-25.

Haraway, D. Staying with the trouble: making kin in the Chthulucene. Durham/London: Duke University Press, 2016.

Kant, I. Crítica da Razão Prática. Trad. Valério Rohden. São Paulo: Martins Fontes, 2002.

Latour, B. Jamais fomos modernos. Trad. Carlos Irineu da Costa. Rio de Janeiro: Editora 34, 2. ed., 2009.

Latour, B. L'Anthropocène et la destruction de l'image du Globe. In: Hache, É. (Org.). De L'Univers Clos au Monde Infini. Paris: Éditions Dehors, 2014. p. 29-56.

Latour, B. Où aterrir. Paris: La Decouvert, 2017 [edição kindle].

Malm, A. Fossil Capital: the rise of steam power and roots of global warming. London/New York: Verso, 2016.

Malm, A. O Mito do Antropoceno. Piseagrama, 8, 24-31, 2015. Disponível em: https://piseagrama.org/o-mito-do-antropoceno/

Maniglier, P. Calcul à cultures: le "structuralisme» dans l'histoire de l'intelligence artificielle. Education \& Didactique, 1(3), 79-104, 2007.

Mbembe, A. Necropolitica. Trad. Renata Santini. São Paulo: n-1, 2018.

Mitchell, T. Carbon Democracy: political power in the age of oil. London/New York: Verso, 2011.

Moore, J. Capitalism in the web of life: ecology and the accumulation of capital. London: Verso, 2015.

Stengers, I. Penser à partir du ravage écologique. In: Hache, É. (Org.). De L'Univers Clos au Monde Infini. Paris: Éditions Dehors, 2014. p. 147-190.

Stengers, I. No tempo das catástrofes. Trad. Eloísa Ribeiro. São Paulo: Cosac Naify, 2015. 
Tsing, A.; Swanson, E. G.; Bubandt, N. (Eds.). Arts of Living on a Damaged Planet. Minneapolis/London: University of Minnesota Press, 2017.
Valentim, M. A. Extramundanidade e Sobrenatureza: ensaios de ontologia infundamental. Desterro: Cultura \& Barbárie, 2018. 